\title{
Desventajas de la introducción de la leche de vaca en el primer año de vida
}

\author{
L.N.C.P. Sara Guillén-López, Dra. Marcela Vela-Amieva
}

\section{RESUMEN}

El costo de las fórmulas infantiles suele ser una de las principales razones por las que las madres prefieren el uso de leche entera de vaca en menores de un año; sin embargo, su empleo en niños de esa edad puede causar daños en la salud. El objetivo de este trabajo es revisar la evidencia científica sobre los riesgos y efectos adversos de alimentar con leche entera a los lactantes antes del primer año de vida. La leche entera de vaca no es una fuente significativa de ácido ascórbico y hierro; este hecho y los microsangrados intestinales que elevan considerablemente el riesgo de causar anemia. La leche de vaca tiene menor contenido de ácidos grasos esenciales que son necesarios para el neurodesarrollo y para la función visual de lactante; por esta razón la leche descremada es menos recomendable. El alto contenido de proteína y nutrimentos inorgánicos da una alta carga de solutos renales, la que en ciertos casos puede causar deshidratación. En ocasiones los lactantes pueden tener alergia a la proteína de la leche. Si bien hacen falta más estudios, existe un número creciente de evidencias que vinculan la introducción temprana de la leche de vaca con algunas enfermedades crónico-degenerativas en los niños tales como la diabetes y la obesidad.

Palabras clave: Leche de vaca, primer año de vida, efectos adversos de la leche de vaca, nutrición del lactante.

\section{ABSTRACT}

The relatively high cost of infant formula compared to cow's milk is one of the main reasons why the latter is widely used. There's a lack of information among health professionals regarding cow's milk in the first year of life, for which reason the aim of this work is to review the scientific evidence related to the adverse effects and risks of the consumption of cow's milk before the first year of age. Cow's milk is not a significant source of ascorbic acid nor iron. In addition there is the risk of gastrointestinal bleeding and anemia. Cow's milk has a low content of essential fatty acids in cows' milk composition; it is well known that these fatty acids, which are necessary for infant's neurodevelopment and visual function; therefore, skimmed milk is not recommended. The high renal solute load which means a high protein and mineral content in milk can cause in some cases dehydration and serious health problems. Some infants may develop allergy to the protein of cow's milk. More studies are needed to establish the relationship between the development of chronic diseases and cow's milk. Recent and increasing data suggest a cause-effect relation for diabetes and obesity among other diseases with the use of cow's milk.

Key words: Cow's milk, first year of life, adverse effects, newborn nutrition.

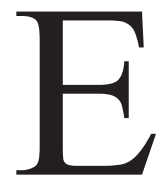

n México es común que los lactantes sean alimentados con leche de vaca ya sea en su presentación líquida como en polvo. La situación económica propicia el uso de estas

\footnotetext{
Laboratorio de Errores Innatos del Metabolismo y Tamiz, Instituto Nacional de Pediatría.
}

Correspondencia: Lic. Sara Guillén-López, Laboratorio de Errores Innatos del Metabolismo y Tamiz, Torre de Investigación del Instituto Nacional de Pediatría. Av. IMAN \# 1- $9^{\circ}$ piso, Col. Insurgentes-Cuicuilco, Del. Coyoacán, C.P. 04530, México, D.F. (55)56-06-32-31.

Correo electrónico: sara_guillen@hotmail.com

Recibido: febrero, 2010. Aceptado: abril, 2010.

Este artículo debe citarse como: Guillén-López S, Vela-Amieva M. Desventajas de la introducción de la leche de vaca en el primer año de vida. Acta Pediatr Mex 2010;31(3):123-128.

www.nietoeditores.com.mx

presentaciones debido a que son más baratas que las fórmulas maternizadas, pero el costo-beneficio y los daños que pueden ocasionar a largo plazo resultan ser más caros comparados con la leche materna y con las fórmulas infantiles.

Los expertos en nutrición infantil consideran que la leche entera de vaca no debe ser introducida en la dieta de los niños menores de un año de edad; sin embargo, algunos autores sugieren que puede darse un poco antes, entre el noveno y décimo mes de vida ${ }^{1-4}$. Otros autores consideran que se pueden agregar pequeñas cantidades de leche de vaca a los principales alimentos de los niños menores de un año ${ }^{5-7}$ (Cuadro 1). En México el Primer Consenso Nacional sobre Alimentación en el primer año de vida recomienda que la introducción de leche de vaca sea después del año de edad ${ }^{8}$; sin embargo, los médicos no siempre conocen las consecuencias que 
Cuadro 1. Comparación de las recomendaciones sobre la introducción de leche entera de vaca en la nutrición infantil

\begin{tabular}{|c|c|c|c|}
\hline País & $\begin{array}{c}\text { Edad recomendada para la } \\
\text { introducción } \\
\text { de la leche de vaca }\end{array}$ & Referencia bibliográfica & Observación \\
\hline Dinamarca & 9 meses & $\begin{array}{l}\text { The National Board of health } \\
\text { Denmark, } 1998\end{array}$ & \\
\hline Canadá & 9 meses & $\begin{array}{l}\text { Canadian Paediatric Socie- } \\
\text { ty. Dieticians of Canada and } \\
\text { Health Canada, } 1998\end{array}$ & \\
\hline Suecia & 10 meses & $\begin{array}{l}\text { Axelsson I, Gebre-Medhin } \\
\text { M, Hernell O, Jackobsonn I, } \\
\text { Michaelsen KF, Samuelson } \\
\text { G, } 1999\end{array}$ & \\
\hline Reino Unido & No es específico & $\begin{array}{l}\text { Department of Health Report } \\
\text { on Health and Social Subjects, } \\
1994\end{array}$ & $\begin{array}{l}\text { No Introducir leche como bebida princi- } \\
\text { pal, sí puede ser agregada a alimentos } \\
\text { complementarios }\end{array}$ \\
\hline $\begin{array}{l}\text { Estados Unidos de Nor- } \\
\text { teamérica }\end{array}$ & No es especifico & $\begin{array}{l}\text { American Academy of Pedia- } \\
\text { trics, } 1992\end{array}$ & \\
\hline
\end{tabular}

tiene la introducción temprana de dicho alimento en la alimentación de los infantes. El objetivo de este escrito es revisar los fundamentos teóricos y las evidencias sobre los riesgos y efectos adversos de la introducción temprana de leche de vaca en las dietas infantiles, haciendo énfasis en los beneficios de la lactancia materna, y en su defecto, el uso de sucedáneos para los menores de un año de edad.

\section{ANEMIA Y LECHE DE VACA}

La leche de vaca no es una fuente importante de hierro, ya que contiene una cantidad baja de este elemento (aproximadamente 0.1 a $0.2 \mathrm{mg}$ de hierro en $100 \mathrm{~g}$ de alimento crudo en peso neto). Además, el hierro de la leche de vaca es del tipo no hematínico, cuya absorción está sujeta a factores dietéticos que pueden inhibirla, tales como la caseína, el calcio, las proteínas del suero y los fosfatos. Otra desventaja es que contiene poco ácido ascórbico ( $0.8 \mathrm{a} 1.0 \mathrm{mg}$ en $100 \mathrm{~g}$ de alimento crudo en peso neto), mismo que aumenta la absorción del hierro, por lo que su consumo debe ser óptimo ${ }^{11,12}$.

La leche de vaca ofrece un buen aporte de calcio: $286.2 \mathrm{mg}$ por una taza de $240 \mathrm{~mL}^{9}$, que cubre alrededor del $120 \%$ de la IDR (ingesta diaria recomendada) para la población mexicana de lactantes de 0 a 12 meses ${ }^{10}$. También da un buen aporte de energía y proteínas; sin embargo, tiene más inconvenientes que ventajas para este grupo de edad, puesto que el calcio compite con la absorción de hierro no hematínico en las células de las mucosas intestinales ${ }^{13,14}$.

La más evidente de las manifestaciones de la deficiencia funcional de hierro es la anemia ferropriva o ferropénica en niños menores de un año y preescolares, lo que se asocia con retraso del crecimiento, alteración en desarrollo psicomotor y cognitivo; además, repercute en etapas posteriores de la vida ${ }^{15}$.

La ENSANUT 2006 incluye datos de niños preescolares de 12 a 59 meses de edad, los cuales se dividieron en 4 grupos de edad, el grupo con mayor prevalencia de anemia en el país fue el de 12 a 23 meses (37.8\%), y los estados con mayor prevalencia de anemia grave fueron: Baja California Norte (36.6\%); Baja California Sur (31.8\%), Guerrero (32.7\%), Sinaloa (34.5\%) y Sonora (30.9\%) ${ }^{16,17}$.

Una encuesta realizada en Cuba en el 2001 en 160 niños, encontró que el factor etiológico más común para el desarrollo de anemia en población de 0 a 1 año de edad era la alimentación con leche de vaca en un $44 \%$ de ellos ${ }^{18}$. Un estudio inglés en 928 lactantes mostró que el consumo de leche de vaca como bebida principal se asociaba con anemia a los 12 meses de edad y niveles bajos de ferritina a los 8 y 12 meses de vida. También se encontró que la ingestión mayor de $600 \mathrm{~mL}$ de leche de vaca al día en lactantes mayores de seis meses disminuía el consumo de alimentos sólidos y en consecuencia, menor aporte de hierro ${ }^{19}$.

La leche de vaca en la dieta del lactante puede causar microsangrados intestinales con pérdida de sangre oculta 
en heces por daño en la mucosa intestinal, que puede ocurrir en $40 \%$ de lactantes normales que reciben leche de vaca. Hay informes que señalan hasta $46 \%{ }^{14,20}$. La leche de vaca "bronca" se relaciona más con sangrado gastrointestinal ${ }^{5,21}$.

La OMS y otros organismos internacionales recomiendan la alimentación exclusiva con leche materna, al menos los primeros seis meses de vida. La leche materna provee de múltiples beneficios al lactante; aunque su contenido de hierro no es alto $(0.35 \mathrm{mg} / \mathrm{L})$, este se absorbe y se utiliza de forma más eficiente, es decir tiene mejor biodisponibilidad que el hierro de la leche de vaca. En general los nutrimentos inorgánicos como el calcio, se absorben mayormente, ya que se ligan a proteínas digeribles como las proteínas de suero, además de presentar estados ionizados y complejos de fácil disponibilidad biológica.

\section{TIPO DE LÍPIDOS Y LECHE DE VACA}

La composición de la leche de vaca difiere mucho de la de la leche materna, ya que contiene mayor cantidad de proteína y nutrimentos inorgánicos; menores cantidades de zinc, vitamina $\mathrm{C}$, vitamina $\mathrm{E}$ y niacina. La grasa saturada se encuentra en mayor cantidad, con una composición diferente de ácidos grasos poliinsaturados de cadena larga; tiene menor cantidad de ácidos grasos esenciales, bajas cantidades de ácido alfa linolénico ${ }^{22}$.

El aporte elevado de grasa saturada en la dieta conlleva el riesgo del desarrollo de enfermedades crónico degenerativas tales como la ateroesclerosis, en etapas posteriores de la vida. La leche humana contiene ácido araquidónico y docosahexaenoico a diferencia de la leche de vaca; estos ácidos grasos son esenciales para el neurodesarrollo y la función visual del lactante ${ }^{5,23}$; la absorción de los lípidos es mayor en el lactante alimentado al seno materno que el que recibe leche de vaca o sucedáneos de la leche materna.

Las madres que dan a sus hijos menores de un año de edad leche de vaca baja en grasas o "light", corren el riesgo de tener deficiencia de ácidos grasos ó incluso retraso del crecimiento debido a la restricción de energía que aporta la grasa $^{22}$. La recomendación de la Asociación Americana de Pediatría es incluir la leche semidescremada o descremada en niños mayores de dos años de edad.

La clasificación de las bebidas en las "Recomendaciones sobre el consumo de bebidas para la población mexicana" se basa en el contenido energético, el valor nutricio y los riesgos a la salud, con una escala del 1 para las más recomendables al 6 para las menos recomendables; el comité respectivo propone a la leche de vaca entera en el nivel 5, tomando en cuenta la cantidad de grasa saturada que contiene y su relación con el desarrollo posterior de enfermedades cardiovasculares ${ }^{24}$.

\section{CARGA DE SOLUTOS RENALES DE LA LECHE DE VACA}

La leche de vaca tiene una elevada carga de solutos, mayor que la de la leche humana, ya que tiene de dos a tres veces más proteína y nutrimentos inorgánicos como sodio, potasio, cloro, fósforo; además no es adecuada para la capacidad de filtración glomerular del lactante. Lo anterior es causa de una mayor concentración urinaria y si el lactante no recibe la cantidad de líquidos adecuada o sufre altas pérdidas extrarrenales de agua, la capacidad del riñón de concentrar la orina en menores de un año es insuficiente para mantener un adecuado balance hídrico y será negativo; ocurrirá una deshidratación muy grave ${ }^{25}$. Puede dar lugar a deshidratación e hipernatremia ${ }^{5}$. En menores de cuatro meses, las altas concentraciones de calcio y de fósforo en la leche de vaca pueden causar hipocalcemia e incluso hipomagnesemia por incremento en la pérdida de calcio, lo que a su vez genera crisis convulsivas. ${ }^{26}$ La proporción de proteína de suero y caseína es de 70 y $30 \%$ respectivamente en la leche humana; en la leche de vaca es $82 \%$ caseína y $18 \%$ proteínas de suero, la relación se invierte completamente, lo anterior es relevante debido a que ambas fracciones tienen propiedades físico-químicas diferentes. La caseína es menos soluble y cuando no ha sido tratada tiende a forma coágulos. Las proteínas del suero son más solubles, se digieren más fácilmente y por lo tanto el vaciamiento gástrico es más rápido; además, el aminograma de la alfa lactoalbúmina es alto en aminoácidos esenciales, y tiene concentraciones mayores de taurina y cisteína. Entre las proteínas del suero, la alfa lactoalbúmina predomina en la leche humana a diferencia de la leche de vaca cuya concentración es principalmente de beta lactoglobulina. La leche humana tiene además una proporción más alta de nitrógeno no proteico. (Cuadro 2) 
Cuadro 2. Características nutrimentales de la leche de vaca y su repercusión en el lactante menor de 1 año

\begin{tabular}{|c|c|c|}
\hline Nutrimentos & Características específicas & Consecuencia o repercusión en la salud \\
\hline Hidratos de carbono & No contiene oligosacáridos, sólo contiene lactosa & $\begin{array}{l}\text { No tiene efecto en la prevención de infecciones a } \\
\text { diferencia de la leche materna }\end{array}$ \\
\hline \multirow[t]{3}{*}{ Proteínas } & Mayor cantidad de proteína & $\begin{array}{l}\text { Aumenta la carga renal de solutos, riesgo de deshi- } \\
\text { dratación en algunos casos. Excede requerimientos } \\
\text { de proteína de lactantes }\end{array}$ \\
\hline & Mayor proporción de caseína & Menor digestibilidad, vaciamiento gástrico lento \\
\hline & $\begin{array}{l}\text { Mayor cantidad de beta lactoglobulina. Tiene albúmi- } \\
\text { na bovina sérica, inmunoglobulinas bovinas }\end{array}$ & $\begin{array}{l}\text { Aumenta el riesgo de presentar enfermedades } \\
\text { atópicas }\end{array}$ \\
\hline \multirow[t]{2}{*}{ Lípidos } & Mayor cantidad de grasa saturada & $\begin{array}{l}\text { Mayor riesgo a presentar enfermedades cardio- } \\
\text { vasculares }\end{array}$ \\
\hline & Menor cantidad de ácidos grasos esenciales & $\begin{array}{l}\text { Alteraciones en el neurodesarrollo y función visual } \\
\text { del lactante. }\end{array}$ \\
\hline Vitaminas & $\begin{array}{l}\text { Menor cantidad de Vitamina E, D, Vitamina C, } \\
\text { niacina }\end{array}$ & $\begin{array}{l}\text { Deficiencias nutricionales } \\
\text { Enfermedad de Möller Barlow }\end{array}$ \\
\hline Nutrimentos inorgánicos & $\begin{array}{l}\text { Menor cantidad de cinc, } \\
\text { Hierro }\end{array}$ & Anemia ferropénica \\
\hline
\end{tabular}

\section{REQUERIMIENTO ENERGÉTICO Y LECHE DE VACA}

El consumo de grandes cantidades de leche de vaca en la dieta desplaza otros alimentos, lo que puede conducir a deficiencia de nutrimentos inorgánicos o de vitaminas. Un litro de leche de vaca sólo cubre unos dos tercios del requerimiento energético de un lactante de 12 meses ${ }^{5}$.

Un estudio brasileño encontró en un grupo de lactantes que, tanto el gasto energético mínimo, como la tasa metabólica durante el sueño, tuvieron un aumento estadísticamente significativo en bebés alimentados al seno materno y que recibían alimentación complementaria con leche de vaca, comparados con niños alimentados sólo con seno materno. Esto podría propiciar desarrollo de obesidad.

La causa de estos trastornos es el alto contenido de proteína de la leche de vaca misma que contribuye en mayor proporción al efecto termogénico de los alimentos a diferencia de los hidratos de carbono o de los lípidos ${ }^{27}$.

Sin embargo, no hay evidencia convincente de la relación entre obesidad y el consumo de leche de vaca, así como del desarrollo de hipertensión ni de la afectación en el crecimiento lineal ${ }^{1}$.

\section{ENFERMEDAD ATÓPICA Y LECHE DE VACA}

Los lactantes pueden desarrollar alergia a la proteína de la leche por exposición temprana debido a antígenos o macromoléculas que contiene. En México en una población de 1,419 pacientes de 0 a 17 años el 39\% tuvo resultado positivo para la prueba cutánea, mostraron hipersensibilidad sobre todo a: frijol, soya, naranja, pescados, mariscos $y$ leche entera de vaca ${ }^{28}$.

Algunos de los factores que explican esta alergia pueden ser: a) Inmadurez de la barrera no específica o no inmunológica (mucosidad intestinal, peristalsis intestinal, enzimas digestivas, baja producción de ácido gástrico), que alcanza su madurez hasta los dos años de edad ${ }^{29,30}$. b) Inmadurez de la barrera inmunológica, puesto que en los primeros meses de vida se encuentran disminuidas las secreciones exocrinas de IgA e IgM. c) Estructura del epitelio intestinal, que alcanza su madurez hasta los 2 años de edad. d) La microflora intestinal, que en los lactantes alimentados con seno materno es predominantemente de Bifidobacterias, lactobacillus, y tiene gran variedad de microorganismos en los primeros meses de vida ${ }^{31,32}$.

Por todo lo anterior es de vital importancia la lactancia materna exclusiva para prevenir futuras alergias. El lac- 
tante alimentado con leche materna no estará expuesto a proteínas de la leche de vaca y su sistema inmunológico madurará, lo que reducirá el desarrollo de enfermedades atópicas ${ }^{33,34}$.

\section{BENEFICIOS DE LA LECHE MATERNA COMPARADA CON LA LECHE DE VACA}

Varios estudios han demostrado que los lactantes alimentados al seno materno tienen menor riesgo de presentar diabetes tipo I que los que recibieron sucedáneos de leche materna. No se sabe si esto se debe a efectos adversos de las proteínas de la leche de vaca o a las sustancias protectoras en la leche humana que regulan el sistema inmune. Incluso en bebés pretérmino la leche materna es un factor protector contra infecciones y enterocolitis necrosante. La leche humana parece tener un efecto protector contra enfermedades como: botulismo, infecciones urinarias, enfermedades gastrointestinales, de las vías respiratorias, otitis media, enfermedad de Crohn y linfoma.

Ambas leches contienen lactosa como hidrato de carbono principal, pero la leche humana contiene oligosacáridos cuya estructura es similar a los ligandos de antígenos bacterianos específicos por lo que compiten con éstos en la adhesión a células de la mucosa intestinal para prevenir infecciones ${ }^{23}$.

\section{PADECIMIENTOS RELACIONADOS CON LA ALIMEN- TACIÓN TEMPRANA DE LECHE DE VACA}

La enfermedad de Möller Barlow, es similar al escorbuto de los adultos; puede ocurrir en niños de uno a seis años de edad, que no recibieron alimentación al seno materno, y que recibieron leche de vaca en los primeros seis meses. Esta leche es baja en vitamina $\mathrm{C}$, lo cual provoca lesiones gingivales, pérdida del apetito, hemorragias, engrosamiento de las uniones hueso-cartílago, sobre todo en la caja torácica, y cartílagos epifisiales de las extremidades, que se acompaña de intenso dolor en las articulaciones; anemia y fiebre ${ }^{35,36}$.

Otro padecimiento relacionado con el consumo de leche de vaca es el síndrome de Heiner, que consiste en hipersensibilidad a la leche de vaca de etiología incierta, que se caracteriza por: tos, congestión nasal, disnea; otitis, fiebre, cólico, diarrea, vómito, neumonía recurrente, infiltrados pulmonares, hematoquezia, hemosiderosis, anemia por deficiencia de hierro, retardo del crecimiento. $\mathrm{Su}$ diagnóstico se realiza en base a una detallada historia clínica, eosinofilia periférica, precipitinas a la leche, biopsia pulmonar ${ }^{37,38}$.

\section{CONCLUSIONES}

En general no se recomienda ningún otro tipo de leche más que la materna en los primeros seis meses de la vida o en su defecto, sucedáneos de leche materna, los cuales están diseñados específicamente para cubrir en lo posible con los requerimientos nutricios del bebé ${ }^{39}$. No se recomienda el uso de la leche entera de vaca, mucho menos el de leche bronca, leche de cabra en ninguna de sus presentaciones ya sea en polvo o líquida en lactantes de 0 a 12 meses.

Para la correcta nutrición durante el primer año de vida, se deben tomar en cuenta diversos factores como la maduración del tubo digestivo, la naturaleza de los alimentos complementarios y la composición de los alimentos lácteos que el niño reciba.

Es importante que el personal de salud promueva intensamente la lactancia materna como medida de prevención de la anemia, y de enfermedades infecciosas como gastrointestinales y respiratorias, especialmente en aquellos estados de nuestro país con una elevada prevalencia de estos problemas en la infancia.

\section{REFERENCIAS BIBILOGRAFICAS}

1. Agostoni C, Decsi T, Fewtrell M, Goulet O, y cols. Complementary feeding: A Commentary by the ESPGHAN Committe on Nutrition. J Pediatr Gastroenterol Nutr. 2008;46(1):99-110

2. Axelsson I, Gebre-Medhin M, Hernell O, Jakobsonn I, Michaelsen KF, Samuelson G, Recommendations for prevention of iron deficiency. Delay cows' milk intake as a beverage to infants until 10-12 months of age. Läkartidningen. 1999;96:2206-8.

3. The National Board of Health (Denmark). Recommendations for the Nutrition of Infants: Recommendations for Health Personnel (in Danish). Copenhagen, Denmark: The National Board of Health (Denmark). 1998.

4. Canadian Paediatric Society, Dieticians of Canada and Health Canada. Nutrition for Healthy Term Infants. Ottawa, Canada: Minister of Public Works and Government Services. 1998.

5. Fleischer K, Sci M. Cow's milk in complementary feeding, Pediatrics. 2000;106 (5Suppl):1302-3.

6. American Academy of Pediatrics, Committee on Nutrition. The use of whole cows' milk in infancy. Pediatrics. 1992;89:11059.

7. Department of Health. Report on Health and Social Subjects No. 45. Weaning and the weaning diet. London, United Kingdom: HMSO; 1994. 
8. Asociación Mexicana de Pediatría, Primer Consenso Nacional sobre Alimentación en el Primer Año de la Vida. Acta Pediatr Mex. 2007;28(5):213-41.

9. Pérez A, Marván L, Palacios B. Sistema Mexicano de Equivalentes, 1 ${ }^{\text {a }}$. Edición Fomento de Nutrición y Salud A.C.; 2000.

10. Bourges H, Casanueva E, Rosado JL. Recomendaciones de Ingestión de Nutrimentos para la población Mexicana. Bases Fisiológicas. Editorial Médica Panamericana; 2005.

11. Morales J, Babinsky V, Bourges H, Camacho ME. Composición de Alimentos Mexicanos. 1a. Edición. INNSZ; 1999.

12. Olivares M, Pizarro F, Pineda O, Name J, Hertrampf E, Walter T. Milk inhibits and ascorbic acid favors ferrous bis-glycine chelate bioavailability in humans. J Nutr.1997;127:1407-11.

13. Hallberg L, Rossander L, Med, Brune M, Gleerup A. Calcium and iron absorption mecanism of actional importance. Eur $\mathrm{J}$ Clin Nutr. 1992;46(5):317-27.

14. Ziegler EE. Adverse effects of cow's milk in infants. Nestle Nutr Workshop Ser Pediatr Program. 2007;60:185-96.

15. Burden MJ, Westerlund AJ, Armony-Sivan R, Nelson CA et al. An event-related potencial study of attention and recognition memory in infants with iron-deficiency anemia. Pediatrics. 2007; 120(2):e336-45.

16. Olaiz-Fernández G, Rivera-Dommarco J, Shamah-Levy $\mathrm{T}$, Rojas R, Villalpando-Hernández S, Hernández-Ávila M, Sepúlveda-Amor J. Encuesta Nacional de Salud y Nutrición 2006. 2da. Edición. Cuernavaca, México: Instituto Nacional de Salud Pública; 2006.

17. Shamah-Levy T, Villalpando-Hernández S, Rivera-Dommarco JA. Resultados de Nutrición de la Encuesta Nacional de Salud y Nutrición 2006. 1a. Edición. Cuernavaca, México: Instituto Nacional de Salud Pública; 2007.

18. Coronel C. Ferropenia: Un problema ignorado. Rev Cubana Pediatr. 2001;73(1):22-7.

19. Hopkins D, Emmett P, Steer C, Rogers I, y cols. Infant feeding in the second 6 months of life related to iron status: an observational study. Arch Dis Child. 2007;92(10):850-4.

20. Fernández SM, de Morais MB, Amancio OM. Intestinal blood loss as an aggravating factor of iron deficiency in infants aged 9 to 12 months fed whole cow's milk. J Clin Gastroenterol. 2008;42(2):152-6.

21. Ziegler EE, Fomon SJ, Nelson SE. Cow milk feeding in infancy: further observations on blood loss from the intestinal tract. $J$ Pediatr. 1990;116:11-8.

22. Michaelsen KF, Hoppe C, Lauritzen L, Molgaard C. Whole cow's milk: why, what and when?, Nestle Nutr Workshop Ser Pediatr Program. 2007;60:201-16.

23. Emmett P, Rogers I. Properties of human milk and their relationship with maternal nutrition. Early Human Development. 1997;49 (1):S7-S28.

24. Rivera JA, Muñoz-Hernandez O, Rosas-Peralta M, AguilarSalinas CA, Popkin BM, Willett WC. Consumo de bebidas para una vida saludable: recomendaciones para la población mexicana. Salud Pub Mex. 2008;50:172-94.

25. Ziegler EE, Fomon SJ. Potential renal solute load of infant formulas. J Nutr. 1989;119:1785-8.

26. Ramírez-Mayans J, Gelis P, García M, Montijo E, Arnold K, Cervantes $R$, y cols. Manual de fórmulas lácteas, sustitutos y complementos nutricionales usados en pediatría. 3ra Edición. Taller Creativo La Perla; 2007. p. 46-51.

27. Haisma H, Wells J, Andrew W, Duro D, et al. Complementary feeding with cow's milk alters sleeping metabolic rate in breastfed infants. J Nutr. 2005;135:1889-95.

28. Ávila L, Pérez J, Del Río BE, Rosas MA. Hipersensibilidad por prueba cutánea a alimentos en pacientes alérgicos en el Hospital Infantil de México "Federico Gómez". Rev Alergia Mex. 2002;89(6 suppl 1):33-7.

29. Sanderson IR, Walker AW. Uptake and transport of macromolecules by the intestine. En: de Weck AL, Sampson HS (ed). Intestinal immunology and food allergy. New York: Raven Press; 1995. p. 19-36.

30. López H, Reynés J. Asociación Mexicana de Pediatría A.C. Consensos 2: Alimentación en el niño con alergia alimentaria. 1a edición, Ed. McGrawHill; 2005. p. 6-13.

31. Sjögren YM, Jenmalm MC, Böttcher MF, Björkstén B, et al. Altered early infant gut microbiota in children developing allergy up to 5 years of age. Clin Exp Allergy. 2009:39(4):518-26.

32. Penders J, Thijs C, Van den Brandt PA, Kummeling I, et al. Gut microbiota composition and development of atopic manifestations in infancy: the KOALA Birth Cohort Study. Gut. 2007;56(5):661-7.

33. Odijk J, Kull I, Borres M, Brandtzaeg P, et al. Breastfeeding and allergic disease: a multidisciplinary review of the literature (19662001 ) on the mode of early feeding in infancy and its impact on later atopic manifestations. Allergy. 2003;58(9):833-43.

34. Thygarajan A, Burks AW. American Academy of Pediatrics recommendations on the effects of early nutritional interventions on the development of atopic disease. Curr Opin Pediatr. 2008;20(6):698-702.

35. Combs GF. The vitamins. Fundamental aspects in nutrition and health. $2^{\text {nd }}$ ed. Academic Press; 1998.

36. Jacob R. "Vitamin C". En: Shils M, Olson J, Shike M, Ross AC. (eds) Modern Nutrition in Health and Disease. 9a. ed. Lippincott Williams \& Wilkins; 1999. p. 467-83.

37. Sampson HA. Food allergy. J Allergy Clin Immunol. 2003;111:S540-7.

38. Moissidis I, Chaidaroon D, Vichyanond P, Bahna SL. Milkinduced pulmonary disease in infants (Heiner Syndrome). Pediatr Allergy Immunol. 2005;16(6)545-52.

39. American Academy of Pediatrics. Alimentación con fórmula del neonato maduro. En: Kleinman R. Manual de Nutrición Pediátrica. 5ta edición. Edición en español Editorial Intersistemas; 2006. p. 87-97. 